\title{
Controlled trial of intermittent aerosol therapy with sodium 2-mercaptoethane sulphonate in cystic fibrosis
}

\author{
P H WELlER, D INGRAM, M A PREECE, AND D J MATTHEW
}

From the Respiratory Unit, The Hospital for Sick Children, Great Ormond Street, and the Department of Growth and Development, Institute of Child Health, University of London, London

ABSTRACT Twenty-seven patients with cystic fibrosis completed a controlled trial comparing the effects of an inhaled mucolytic drug, sodium-2-mercaptoethane sulphonate (Mistabron, UCB Pharmaceutical Division, Brussels, Belgium), with inhaled iso-osmolar hypertonic saline. As a group the 22 patients with chronic sputum production showed small but statistically significan improvement in pulmonary function tests after Mistabron therapy, both when compared with a control period, and with iso-osmolar saline results. Subjective measurements by diary card failed to show any changes. No significant changes were found in five patients with no measurable sputum production. The inhalations were given after physiotherapy and were well tolerated: There were no significant side effects. The results suggest that Mistabron has a beneficiab therapeutic effect unrelated to its high osmolality, and the intermittent inhalation of Mistabrons may have a role in the treatment of selected patients with cystic fibrosis.

The intermittent inhalation of mucolytic agents is used in the treatment of patients with cystic fibrosis, yet there is little published controlled data reporting their effect. Earlier uncontrolled studies have reported clinical benefit from the use of $\mathrm{N}$-acetylcysteine (NAC). ${ }^{12}$ Sodium 2-mercaptoethane sulphonate (Mistabron) is a similar sulphydryl compound which is believed to reduce sputum viscosity by disrupting disulphide bonds. In vitro studies have shown that Mistabron is more active than $\mathrm{NAC}^{3}$ and it may be more active in vivo. ${ }^{4}$ In a controlled pilot study we found that Mistabron had significant beneficial effects on pulmonary function tests in nine children with cystic fibrosis. In this paper we report the results of a further trial, comparing intermittent inhalations of Mistabron $20 \%$ and iso-osmolar hypertonic saline.

\section{Methods}

Twenty-nine patients with cystic fibrosis entered the trial. Diagnosis was confirmed in all by history, examination, and a sweat sodium of greater than $70 \mathrm{mmol} / 1$ (obtained by pilocarpine iontophoresis).

Address for reprint requests: Dr DJ Matthew, Respiratory Unit, The Hospital for Sick Children, Great Ormond Street, London WC1N 3JH.
Two patients had to be withdrawn from the study $\overrightarrow{\overrightarrow{0}}$ In one this was because of an acute exacerbation? during the second treatment period (saline inhala tions) requiring prolonged hospitalisation, during. which time she received other inhalational treat ment (antibiotics and bronchodilators). The othe patient did not take her inhalations correctly and was admitted to hospital early in the study, during saline therapy, both for more intensive medical treatment and for psychiatric reasons. She alse received other inhalational treatment.

Fourteen females and thirteen males completec the trial and their ages ranged from 6 to 1 ; years (mean $10.7 \mathrm{yr}$ ). Of these 27 patients, 22 were chronic sputum producers. Before entering ths trial, all patients had received routine therapy including twice daily chest physiotherapy (pero cussion and postural drainage), dietary controf pancreatic enzymes, vitamins, and oral antibiotics as indicated, for at least five years and this was continued during the trial. Five patients wers taking continuous oral $\beta_{2}$ adrenergic bronchodilator drugs. Three patients were admitted to hospital during the course of the trial for paro enteral antibiotics and physiotherapy. One of these was an inpatient for most of the trial. The otheq two were admitted electively because of poof growth and persisting respiratory symptoms, ong 
during the initial baseline period and one during the second month of saline treatment. No patient was receiving mist tent therapy or other aerosol therapy.

The trial was of a double-blind crossover design, Mistabron $20 \%$ solution being compared with a $7 \%$ saline solution. Seven per cent saline solution is iso-osmolar with $20 \%$ Mistabron and was chosen in order to assess whether Mistabron had demonstrable action in addition to that which could be attributable to its high osmolality (1.2 molar). Twomonth baseline periods preceded and followed two eight-week treatment periods, with the order of treatment randomised. Three $\mathrm{ml}$ of solution were inhaled twice daily, after physiotherapy, from a Wright nebuliser operated by an air compressor (Aerolyser Electric Inhaler, Aerosol Products (Colchester) Ltd) producing a flow of 8 litres per minute. The aerosol was inhaled through a short, wide bore tube into the mouth, each therapy taking about 10 minutes.

Patients and their parents kept a diary card recording morning and evening physiotherapy sputum volume, sputum colour, and cough frequency for the day. The last was scored on a three-point scale $(1=$ no cough; $2=$ occasional cough; $3=$ frequent cough). Any comments regarding their symptoms or therapy were also noted.

Patients attended each month at the routine clinic. Sputum was cultured and pulmonary function tests performed. Peak expiratory flow rate (PEFR) was measured by Wright peak flow meter, and forced vital capacity (FVC) by reverse plethysmography. Maximum expiratory flow volume curves were obtained by measuring flow at the mouth with a pneumotachograph and the flow signal was integrated to give volume; the result was expressed as maximum flow at $50 \%$ of vital capacity (Vmax50\%VC). Peak expiratory flow rate, FVC, and Vmax $50 \%$ VC were expressed as a percentage of the predicted value for height from our own normal data. ${ }^{5}$ The percentage of residual volume (RV) to total lung capacity (TLC) was calculated and measured by constant volume whole body plethysmography. ${ }^{6}$ Chest radiographs, taken at the beginning and end of the trial, were scored by two independent observers using the score of Chrispin and Norman. ${ }^{7}$ All results were analysed using the $t$ test for paired differences Full blood count, liver function tests, and plasma electrolytes including creatinine, were measured at the beginning and end of the trial.

\section{Results}

The age, chest radiographic scores, and baseline pulmonary function tests (expressed as percentage of the predicted normal for height) for the 27 patients who completed the trial are shown in table 1. Those who did not produce sputum tended to be younger, have lower (that is better) chest radiographic scores and better pulmonary function. Among the sputum producers there was a wide range of abnormality of both chest radiograph and pulmonary function.

Comparing baseline and treatment periods, there were no significant differences in cough frequency, sputum volume, or sputum colour on analysis of the diary cards for sputum producers, nor in cough frequency in the nonproducers. On questioning, several patients noted that the inhalations initially made them cough, this occuring equally at the start of both therapies, but usually settling within days. No untoward effects were noted except that several patients found the inhalations boring and time-consuming. They did not complain about the taste or odour of either inhalation. There was no change in sputum bacteriology - for example, appearance of Pseudomonas aeruginosa -and courses of antibiotics were prescribed as frequently during baseline periods as during either treatment period.

The results of the pulmonary function data are shown for the sputum producers in tables 2 and 3 and for the sputum nonproducers in table 4 . There was no significant difference in pulmonary function for the two measurements obtained during each baseline period, and the mean of these two measurements has been used as the baseline value

Table 1 Age and radiographic scores at start of trial and baseline pulmonary function tests

\begin{tabular}{|c|c|c|c|c|c|c|c|}
\hline & & Age (yr) & $\begin{array}{l}\text { Radiographic } \\
\text { score }\end{array}$ & $P E F R^{*}$ & $F V C^{\star}$ & $\dot{V} \max 50 \% V C^{*}$ & $R V / T L C$ \\
\hline $\begin{array}{l}\text { Sputum } \\
\text { producers } \\
(n=22\end{array}$ & $\begin{array}{l}\text { Mean } \\
\text { SD } \\
\text { Range }\end{array}$ & $\begin{array}{l}10 \cdot 9 \\
2 \cdot 1 \\
6 \cdot 5-15\end{array}$ & $\begin{array}{l}11 \\
6 \\
4-21\end{array}$ & $\begin{array}{l}80 \\
21 \cdot 5 \\
27-113\end{array}$ & $\begin{array}{l}76 \\
15 \cdot 9 \\
38-101\end{array}$ & $\begin{array}{l}51 \\
25 \cdot 8 \\
7-102\end{array}$ & $\begin{array}{l}45 \\
15 \cdot 6 \\
25-78\end{array}$ \\
\hline $\begin{array}{l}\text { Sputum } \\
\text { nonproducers } \\
(n=5)\end{array}$ & $\begin{array}{l}\text { Mean } \\
\text { SD } \\
\text { Range }\end{array}$ & $\begin{array}{l}9 \cdot 8 \\
2 \cdot 8 \\
6 \cdot 1-12 \cdot 25\end{array}$ & $\begin{array}{l}7 \\
2 \\
4-10\end{array}$ & $\begin{array}{l}96 \\
11 \cdot 6 \\
78-107\end{array}$ & $\begin{array}{l}88 \\
10 \cdot 1 \\
76-104\end{array}$ & $\begin{array}{l}70 \\
23 \cdot 2 \\
50-106\end{array}$ & $\begin{array}{l}40 \\
5 \cdot 5 \\
30-43\end{array}$ \\
\hline
\end{tabular}

*Expressed as \% predicted normal 
Table 2 Sputum producers' $(n=22)$ mean pretreatment baseline values and values after Mistabron treatment (SEM in brackets)

\begin{tabular}{lllll}
\hline & Baseline & Mistabron & Change & p value \\
\hline PEFR* & $77(4 \cdot 5)$ & $84(4 \cdot 5)$ & +7 & $<0.02$ \\
FVC* & $76(3 \cdot 2)$ & $79(3 \cdot 2)$ & +3 & $<0.2$ \\
Vmax50\%VC* & $48(4 \cdot 7)$ & $58(5 \cdot 1)$ & +10 & $<0.005$ \\
RV/TLC & $44(3.6)$ & $39(3.2)$ & -5 & $<0.1$ \\
\hline
\end{tabular}

*\% predicted normal

Table 3 Sputum producers' $(n=22)$ mean pre-treatment baseline values and values after saline therapy (SEM in brackets)

\begin{tabular}{lllll}
\hline & Baseline & Saline & Change & $p$ value \\
\hline PEFR* & $81(4)$ & $79(3 \cdot 6)$ & -2 & NS \\
FVC* & $81(3 \cdot 6)$ & $80(3 \cdot 4)$ & -1 & NS \\
Vmax $50 \%$ VC* $^{*}$ & $53(5 \cdot 3)$ & $53(5 \cdot 3)$ & 0 & NS \\
RV/TLC & $40(3 \cdot 0)$ & $41(2 \cdot 8)$ & +1 & NS \\
\hline
\end{tabular}

*\% predicted normal

Table 4 Mean change (SEM in brackets) from baseline to end of therapy, for Mistabron treatment and for saline treatment in sputum nonproducers $(n=5)$

\begin{tabular}{lcll}
\hline & $\begin{array}{l}\text { Change during } \\
\text { Mistabron }\end{array}$ & $\begin{array}{l}\text { Change during } \\
\text { saline }\end{array}$ & $p$ value \\
\hline PEFR* & $0(3 \cdot 4)$ & $+2(4 \cdot 0)$ & NS \\
FVC* & $-1(3 \cdot 1)$ & $+6(3 \cdot 6)$ & NS \\
Vmax50\%VC* & $-5(10 \cdot 3)$ & $+14 \dagger(4 \cdot 6)$ & NS \\
RV/TLC & $0(4 \cdot 4)$ & $-6(4 \cdot 0)$ & NS \\
\hline
\end{tabular}

*\% predicted normal

†The change from baseline to end of saline treatment was significant $(\mathrm{p}<0.05)$

to compare with the values obtained after treatment with Mistabron or saline.

When pre-treatment baseline values were compared with the values after Mistabron treatment, the sputum producers showed significant improvement in PEFR and Vmax $50 \% \mathrm{VC}$ with a trend towards improvement, that is a reduction, in $R V /$ TLC. There was no significant change in FVC (table 2). After saline treatment, there were no significant changes in pulmonary function tests (table 3).

A direct comparison of the changes that occurred during each treatment period showed that PEFR improved significantly during Mistabron treatment $(p<0.005)$ as did RV/TLC $(p<0.02)$, compared with saline treatment. There were no significant differences in FVC and Vmax $50 \%$ VC.

Such a comparison might be deemed invalid because the baseline values before saline treatment indicated better pulmonary function, compared with the baseline values before Mistabron treat- ment. This difference occurred partly by chance $\frac{\text { of }}{0}$ and partly because the RFTs of those patients whof received Mistabron first did not return to a similar value before saline treatment. The difference between the response to Mistabron and the response $\frac{\rho}{\alpha}$ to saline treatments correlated significantly withes the difference in pretreatment baseline values, the $\overrightarrow{0}$ correlation coefficients ranging from -0.43 to $-0.65(n=20)$. Therefore the changes in pul- $\omega$ monary function after each treatment were corrected for pre-treatment baseline values by analysis of covariance. The improvement in PEFR waș found to be significantly greater after Mistabron $\overrightarrow{+}$ treatment than after saline treatment $\left(+6 \% \frac{\stackrel{N}{N}}{\mathrm{~s}}\right.$ $\mathrm{p}<0.02)$, as was the improvement in $\mathrm{RV} / \mathrm{TLC}$ $(-3 \% \mathrm{p}<0.05)$.

In the sputum nonproducers no significantor changes in pulmonary function occurred after: Mistabron treatment, but there was significan improvement in $\operatorname{Vmax} 50 \% \mathrm{VC}$ after saline treat $-\vec{\odot}$ ment $(p<0.05)$. There were no significant differ-o ences when the changes that occurred during each treatment period were compared (table 4).

Full blood count, liver function tests, plasmas electrolytes, and creatinine showed no abnorma changes.

No important adverse effects were noted during either therapy. All patients were given test in $\overrightarrow{\overrightarrow{0}}$ halations of Mistabron and hypertonic saline 3 before entering the study, and none developed wheezing. Two patients had complained of nausea. after a test inhalation of Mistabron and they were not enrolled in the study.

\section{Discussion}

Aerosol therapy has been widely used in the treat ment of cystic fibrosis to deliver particles of watero or various pharmacological agents to the respiratory tract, despite the lack of objective evidenceo confirming any therapeutic effect. The beneficial effects of night mist tent therapy, described byo Matthews et $a l^{8}$ have not been substantiated by others. $^{910}$ Several workers have shown that veryN little of the mist or aerosol is deposited in the ${ }_{\sigma}$ peripheral airways of cystic fibrosis patients ${ }^{11-13<}$ and, in addition, the more severely affected areas? receive less. However, the amount of aerosole reaching the lower respiratory tract may be in 0 creased by the use of a short, wide bore tube intoo the mouth, as used in this study, rather than ad face mask. ${ }^{11}$ We gave the inhalations after physiotherapy in the hope that physiotherapy might have improved the ventilation of the more diseased areas of lung, thereby allowing improved depo-o 
sition within these areas. We have no evidence to substantiate this.

The results demonstrate a small, but statistically significant, improvement in forced expiratory flows after Mistabron therapy in the patients with chronic sputum production. This suggests that Mistabron has facilitated expectoration of sputum from larger airways, where most of the aerosol is likely to be deposited. Subjective improvement of sputum clearance was noted by several patients during Mistabron inhalation, but this was not borne out by diary card scores of sputum volume.

The baseline values before saline therapy tended to indicate better pulmonary function compared with the baseline values before Mistabron therapy. Despite the random allocation of the order of treatment, those patients who received saline inhalations first tended to have better pulmonary function than those who received Mistabron first. Also the patients who received Mistabron first maintained some improvement after finishing Mistabron treatment, indicating a possible carryover effect, with the result that their baseline values were better. However, even when the baselines are corrected, the improvement in pulmonary function after Mistabron therapy is significantly greater than that after saline therapy. Both of these solutions are equally hyperosmolar and both will have some osmotic effect, but the difference noted between the two therapies suggests that Mistabron does have an additional mucolytic action, perhaps by splitting disulphide bonds.

While Mistabron had no significant effect on pulmonary function in the sputum nonproducers, saline therapy did bring some improvement, although there were no significant differences when the two treatments were compared. The numbers in this group are too small to draw definite conclusions but it would appear that Mistabron therapy does not produce the same beneficial effect that was seen in the sputum producers.

Previous reports on the intermittent inhalation of mucolytics in cystic fibrosis are few. In an uncontrolled study of 28 children with cystic fibrosis treated with intermittent NAC inhalations, Reas ${ }^{1}$ noted clinical improvement and improvement in pulmonary function tests. It is interesting that the greatest improvement was seen in those with moderate pulmonary disease, rather than those with mild or severe disease. Denton et $a l^{2}$ noted improvement in upper respiratory symptoms, but no improvement in lower respiratory symptoms, signs, or pulmonary function tests. Phelan et al, ${ }^{14}$ in an uncontrolled study, reported that infants with cystic fibrosis benefited from the inhalation of a mixture containing propylene glycol, orciprenaline, and antibiotic. Abnormal hyperinflation and airways resistance returned to normal after therapy. Thus, there is no controlled study demonstrating a definite beneficial effect of NAC or other mucolytic agents on the lower respiratory tract.

The prolonged use of Mistabron in cystic fibrosis has not been reported previously. Studies in adults with chronic bronchitis ${ }^{3415}$ have shown that the drug produces a reduction in sputum viscosity and an increase in sputum volume, but no improvement in pulmonary function tests.

Few side effects have been reported with its use. ${ }^{15}$ Those reported include wheezing, nausea, and vomiting, and yellow staining of teeth with prolonged use. No significant adverse effects were noted during this study, including any further staining of teeth.

In conclusion, we have demonstrated a small but significant improvement in pulmonary function after Mistabron therapy, in patients with chronic sputum production. The inhalations were well tolerated. We suggest that this therapy should be considered for use in cystic fibrosis patients with chronic sputum production, and that individual responses should be carefully monitored and used to determine whether treatment should be continued.

We thank Dr ADM Jackson for allowing us to study patients under his care.

\section{References}

1 Reas HW. The use of $\mathrm{N}$-acetylcysteine in the treatment of cystic fibrosis. J Pediatr 1964; 65: 542-57.

2 Denton R, Kwart H, Litt M. N-Acetylcysteine in cystic fibrosis. Am Rev Respir Dis 1967; 95:64351.

3 Hirsch SR, Zastrow JE, Kory RC. Sputum liquefying agents: a comparative in vitro evaluation. J Lab Clin Med 1969; 74:346-53.

4 Hirsch SR, Viernes PF, Kory RC. Clinical and physiological evaluation of mucolytic agents nebulised with isoproterenol: $10 \% \mathrm{~N}$-acetylcysteine versus $10 \% 2$-mercaptoethane sulphonate. Thorax 1970; 25:737-43.

5 Cogswell JJ, Hull D, Milner AD, Norman AP, Taylor B. Lung function in childhood. 1. The forced expiratory volumes in healthy children using a spirometer and reverse plethysmograph. Br J Dis Chest 1975; 69:40-50.

6 Dubois AB, Botelho SY, Bedell GN, Marshall R, Comroe JH Jr. A rapid plethysmographic method of measuring thoracic gas volume; a comparison 
with a nitrogen washout method for measuring functional residual capacity in normal subjects. J Clin Invest 1956; 35:322-9.

7 Chrispin AR, Norman AP. The systematic evaluation of the chest radiograph in cystic fibrosis. Pediatr Radiol 1974; 2:101-6.

8 Matthews LW, Doershuk CF, Spector S. Mist tent therapy of the obstructive pulmonary lesion of cystic fibrosis. Pediatrics 1967; 39:176-84.

9 Motoyama EK, Gibson, LE, Zias CJ. Evaluation of mist tent therapy in cystic fibrosis using maximum expiratory flow volume curve. Pediatrics 1972; 50:299-306.

10 Chang N, Levison $\mathrm{H}$, Cunningham $\mathrm{K}$, Crozier DN, Grosett $O$. An evaluation of nightly mist tent therapy for patients with cystic fibrosis. $\mathrm{Am}$ Rev Respir Dis 1973; 107:672-5.

11 Wolfsdorf J, Swift DL, Avery ME. Mist therapy reconsidered: an evaluation of the respiratory deposition of labelled water aerosols produce? by jet and ultrasonic nebulisers. Pediatrics 1969은 43:799-808.

12 Bau SK, Aspin N, Wood DE, Levison H. Th measurement of fluid deposition in humans fole

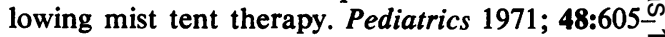
12.

13 Alderson PO, Secker-Walker RH, Strominger DB Markham J, Hill RL. Pulmonary deposition of aerosols in children with cystic fibrosis. $J$ Pediat: 1974; 84:479-84.

14 Phelan PD, Gracey M, Williams HE, Andersorfy CM. Ventilatory function in Infants with cystic fibrosis. Arch Dis Child 1969; 44:393-400.

15 Steen SN, Ziment I, Freeman D, Thomas JS Evaluation of a new mucolytic drug. Clin Phar? macol Ther 1974; 16:58-62.

\section{Second World Congress on Lung Cancer}

The 2nd World Congress on Lung Cancer, sponsored by the International Association for the Study of Lung Cancer, will be held in Copenhagen-Malmö from 9 to 13 June 1980. Topics to be covered include epidemiology, early diagnosis and staging, pathology, cellular kinetics, tumour markers, and all modalities of treatment such as surgery, radiotherapy, chemotherapy, and immunotherapy. Further information may be obtained from DIS Congress Service, Linde Alle 48, DK-2720 Vanløse, Denmark (tel: 01-11 00 44), or from Secretary-General, Heine H Hansen, MD, Finsen Institute, Strandboulevarden 49, DK-2100 Copenhagen, Denmark (tel: $01-260850$ ext 256 or 266). 